$124(95 \%)$ reported this as viral-induced, 25 (19\%) had more than 3 attacks of wheeze, 31 (24\%) were prescribed inhalers and $20(15.4 \%)$ reported having disturbed sleep once or more nights per week. $156(17 \%)$ infants required hospital admission in their first 6 months of life, with 36/938 (4\%) requiring more than one admission. Of the children experiencing any hospital admission, $17 \%$ received oral antibiotics, while $24 \%$ received intravenous antibiotics. 646 (69\%) infants had visited the GP at least once, of whom 93 (14\%) received antibiotics for probable infections. $95 \%$ of the participants returning the 6-month questionnaire were fully immunised.

Conclusion Despite the possible bias of those returning questionnaires, our interim results indicate a high prevalence of infection and wheeze during the first 6 months of life in UK infants. Approximately $14 \%$ had experienced wheeze, $14 \%$ received oral antibiotics from the GP and 17\% reported being admitted to hospital. We wish to further explore the association of genetic variations and their interactions in the context of childhood infections and atopy.

The study was funded by the children's charity SPARKS.

\section{G395(P) EXPERIENCES OF PATIENTS ON LONG TERM VENTILATION TRANSFERRING TO ADULT SERVICES}

${ }^{1} \mathrm{O}$ Narayan, ${ }^{1} \mathrm{~S}$ Bajgoric, ${ }^{2}$ C Cecil-Oakes, ${ }^{3} \mathrm{~S}$ Whitfield, ${ }^{3} \mathrm{~A}$ Thomas, ${ }^{1} \mathrm{M}$ Samuels. ${ }^{1}$ Academic Paediatrics, Royal Stoke University Hospital, Stoke-on-Trent, UK; ${ }^{2}$ School of Medicine, Keele University, Stoke-on-Trent, UK; ${ }^{3}$ Department of Respiratory Medicine, Royal Stoke University Hospital, Stoke-on-Trent, UK

\subsection{6/archdischild-2015-308599.349}

Aims Medical advances mean that more children with serious illnesses are surviving into adulthood. Recent legislation and guidelines stress the importance of delivering improved joinedup services for children undergoing transition to adult services. ${ }^{1,2}$ A qualitative study was performed to explore the experiences of patients receiving long-term ventilation (LTV).

Methods Questionnaire-based telephone interviews were conducted with 21 patients (14 males, median age 26 years, range 14-57) on LTV or their carers. All had previously been within children's services and were now under adult respiratory care at a UK teaching hospital. The underlying causes for LTV included: Duchenne muscular dystrophy (9), other muscular dystrophies (6), congenital central hypoventilation syndrome (4) and other (2).

Results Thematic analysis of the data identified 3 main themes:

1. Variability: the age at which transition occurred varied (17-25), as did the option to attend combined clinics, which was only given to 3 of the 21 patients. There were discrepancies in the provision of community services, which was described as being "post-code dependent".

2. Unfamiliarity: patients expressed concerns about the unfamiliarity of adult doctors with their background and condition, which was often interpreted as insensitivity or lack of knowledge. They expressed frustration at having to repeat their story to numerous health care professionals.

3. Separation of services: care under children's services was reported as being more holistic when compared with the single organ approach in adult services. However, the thoroughness of adult physicians in patient management was appreciated.

Conclusion Our study highlights the gap that needs to be bridged between children and adult services for patients on LTV. Early transition planning should occur to alleviate the unfamiliarity commonly experienced. This should include information about adult care and the differences in service provision. The utilisation of health care passports can do much to avoid physician unfamiliarity with the patient's situation. These changes need to be uniformly adopted in order to improve patient satisfaction, care and long term outcome.

\section{REFERENCES}

1 Care Act 2014

2 Care Quality Commission. From the pond into the sea: Children's transition to adult healthcare services. June 2014

\section{G396(P) IS INFANTILE LARYNGOMALACIA ASSOCIATED WITH EARLY ONSET ADENOTONSILLAR HYPERTROPHY: A RETROSPECTIVE PILOT STUDY}

LA Murphy, SC Tan, M Wickham, A Clements, H Kubba. Ear, Nose and Throat Department, Royal Hospital for Sick Children, Glasgow, UK

\subsection{6/archdischild-2015-308599.350}

Introduction Laryngomalacia has been associated with gastroesophageal reflux (GOR), which may cause adenotonsillar hypertrophy leading to early onset obstructive sleep apnoea (OSA). We aim to assess this proposed relationship, with adenoidectomy $<4$ years as our primary endpoint.

Method 78 children seen in the airway clinic at the Glasgow Royal Hospital for Sick Children during September 2009 to August 2010 with a diagnosis of infantile laryngomalacia and for whom four years of follow up data was available were included, and their medical notes analysed.

Results We found a significantly increased incidence of OSA in our cohort of $11.5 \%$, compared to a reported population incidence of $0.7-1.8 \%(\mathrm{p}=<0.0001)$. The rate of adenoidectomy $<4$ years in this sample was $12.8 \%$. We found that children who undergo adenoidectomy are more than $4 \mathrm{x}$ likely to also undergo a supraglottoplasty procedure than those who do not, $70 \%$ vs. $16.2 \%(p=0.0008)$. Significant increase in the presence of neurodisability in the group of children who underwent an adenoidectomy was also seen, $40 \%$ vs. 2.9\% ( $\mathrm{p}=<0.002$ ).

Conclusion Outcomes following adenoidectomy +/- tonsillectomy are suggestive of adenotonsillar hypertrophy being the leading cause of OSA. Our results also support an emerging link between GORD and OSA, as although there are a number of causes of adenotonsillar hypertrophy there was little evidence to suggest that any of these patients could have developed hypertrophy due to alternative mechanisms. Children with more severe laryngomalacia appear to be at higher risk of developing sleep disordered breathing symptoms, and subsequently requiring adenoidectomy.

\section{G397(P) HYPOXIC CHALLENGE TESTING - WHICH CHILDREN ARE WE ASSESSING?}

E Caffrey Osvald, A Midgley-Hunt, JR Clarke. Respiratory Department, Birmingham Children's Hospital, Birmingham, UK

\subsection{6/archdischild-2015-308599.351}

Aim Hypoxic challenge testing (HCT) is the method used to assess whether a patient with stable respiratory disease requires in-flight oxygen. A national guideline, published by British Thoracic Society in 2011, makes recommendations on which children ought to undergo HCT prior to undertaking air travel. Identified are: infants under 1 year with neonatal history of 
chronic lung disease, children with $\mathrm{CF} /$ chronic lung disease old enough for spirometry whose FEV1 $<50 \%$, and infants/children who required long term oxygen in the last 6 months.

This audit aimed to define which patients had undergone hypoxic challenge tests and compared this against the patient groups identified in the BTS guideline.

Methods A large tertiary children's hospital in the UK conducted a retrospective audit of hypoxic challenge tests carried out between 2012 and 2014.

Information was collected on age, diagnosis, when the patient last required long-term oxygen, lung function around the time of the test and the outcome of the test.

Results 31 HCTs from 25 patients were audited. The average age was 6.3 years (6 months-16.5 years).

Of the 22 patients who passed the HCT, three were recommended in the guideline to have HCT. Of the nine patients who did not pass HCT, two were within the recommendations.

These five patients, who were within the recommendations, were three children with $\mathrm{CF} /$ chronic lung disease with FEV1 </ $=50 \%$, one infant less than one year with history of neonatal chronic lung disease, and one child had a long term oxygen requirement within 6 months prior to testing.

Of the nine children who did not pass the HCT, seven fell outside the recommended groups. Five were ex-preterm children older than one year had history of neonatal chronic lung disease, one had SMA Type 2, one had muscular dystrophy, one had severe kyphoscoliosis and one had severe restrictive lung disease following PNET.

Conclusion Results show that clinicians are choosing to preform hypoxic challenge tests on patient outside of the recommendations. A larger proportion who failed the hypoxic challenge test were not defined within the BTS guidelines.
With advancing technology the demographics of our respiratory paediatric patient population is evolving. It is therefore prudent to reconsider the paediatric recommendations.

\section{G398(P) USE OF VIDEO, SOUND AND PULSE TRANSIT TIME TO IMPROVE ACCURACY OF SCREENING FOR OBSTRUCTIVE SLEEP APNOEA IN CHILDREN}

NJ Rowbotham, H Dove, MP Yanney. Paediatrics, Sherwood Forest Hospitals, Sutton-inAshfield, UK

\subsection{6/archdischild-2015-308599.352}

Aims Oximetry is widely used to screen for obstructive sleep apnoea (OSA) in children with good specificity but reduced sensitivity compared to polysomnography (PSG). ${ }^{1}$ Treatment decisions are usually made using oximetry criteria alone. ${ }^{2}$ Our aim is to investigate whether screening sleep studies incorporating extra modalities improve the accuracy of detecting OSA compared to oximetry alone.

Methods A retrospective review of 197 inpatient sleep studies performed at a district general hospital in 2013 was carried out using data from patient notes and a database. The sleep studies were performed with VISILAB equipment incorporating ECG, audio, video, pulse transit time (PTT) and oximetry. Study findings were categorised as 'normal'; 'primary snoring'; 'upper airway resistance syndrome' (UARS); 'obstructive sleep apnoea' or 'other abnormality'. The findings are compared with oximetry risk categories using standard criteria for OSA screening.

Results The main findings are shown in Figures 1 and 2.

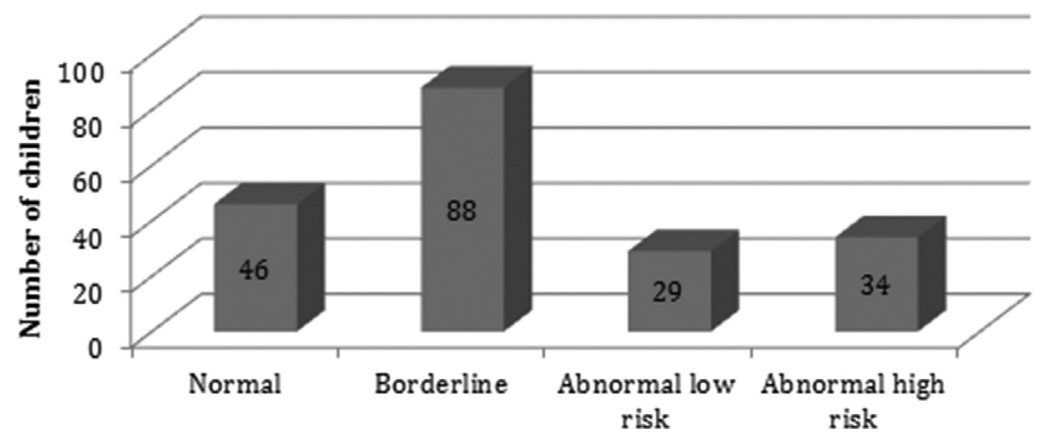

Abstract G398(P) Figure 1 Categories of risk based on oximetry data

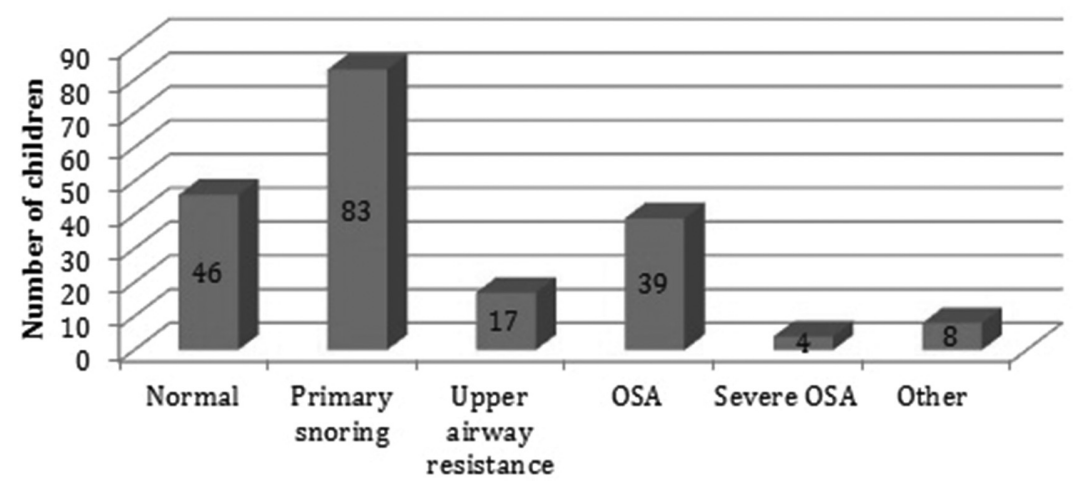

Abstract G398(P) Figure 2 Diagnosis based on sleep study findings 